\title{
Registry based perinatal epidemiology: The importance of sibling and generation data
}

\author{
Rolv Skjærven \\ Department of Global Public Health and Primary Care, University of Bergen, Bergen, Norway \\ Medical Birth Registry of Norway, Norwegian Institute of Public Health, Bergen, Norway \\ E-mail: rolv.skjarven@uib.no
}

\section{UNIQUE DATA FOR REPRODUCTIVE EVENTS}

For more than three decades, sibship organized data from the Medical Birth Registry of Norway have been the basis for studies of variation of pregnancy outcome. Also, more recently, the registry has allowed two-generation links of birth records. These population based linked materials provide research opportunities that go beyond those based on cross-sectional collections of birth records. The agenda has been pregnancy problems like preeclampsia and other maternal complications during pregnancy, and outcome of pregnancy in terms of preterm birth, low birthweight, stillbirth, malformations and infant's survival and morbidity, and more. More recently, studies have started considering how problems in pregnancy may predict the mother's and the father's long-term morbidity and mortality. For example, women die at younger ages if they have delivered preterm, if they have had a child with low birth weight, or if they have developed pre-eclampsia during pregnancy. In other materials, these observations have typically been based on studies of the woman's first pregnancy. One problem with this first pregnancy approach is that women who stop reproducing after one pregnancy have in general higher mortality than women with two or more pregnancies (1).

Much of what we study is related to complications in pregnancy. The chances that a woman has a next pregnancy are contingent on the outcome of prior pregnancies in several important ways: women with a medically complicated pregnancy may be advised or choose to avoid further pregnancies; women who are mothering children with health impairments resulting from perinatal complications may be too overwhelmed to bear another child; and underlying medical factors (such as insulin resistance or vascular dysfunction) associated with pregnancy complications may also be associated with secondary infertility. These factors add up to a strong potential of selection bias when only first births are considered. Few studies have yet considered how this selection may distort the long-term associations of reproduction with women's later health.

It seems that studies of pregnancy outcome and long term health aspects both for the child and the mother by large benefit from the reproductive data of the mother: risks related to the pregnancy or the child need to be evaluated through knowledge of the mother's previous pregnancies, while long term risks related to the mother herself calls for her complete reproductive history. In the light of the hypothesis of mother-child (genetic) conflict, a condition that improves the child's development, may not always be beneficial to the mother's health. One such suggested condition is preeclampsia (2).

In general, the Nordic countries have unique prospects for epidemiological research given the population based health registries, with compulsory notification, in which the records are identified by the national identification number, enabling internal and external record linkage. Sibling related data, as well as generation data, are excellent examples how we in Norway have genuine research advantages. The long lasting registration of all births provides a setting for studies of variation of longevity of mothers and fathers as a function of their complete reproductive history. Such data are almost impossible to achieve outside the Nordic countries. Thus, we have, not only a unique opportunity, but an obligation to investigate the prospects of these linked data. In fact, much of the Norwegian success in the perinatal epidemiological research is due to these data qualities. We will present examples of results that cannot be achieved using conventional cross-sectional data.

The Medical Birth Registry of Norway (MBRN) is the world's first of its kind, established in 1967. Soon covering 50 years of births in Norway, analyses that deal with time trends or long term follow-up of children and parents have an advantage. Long term health effects of being born with a specific condition, for instance being born preterm $(3,4)$, and long term health effects for women after complications in pregnancies, like preeclampsia and kidney disease are examples of excellent research that have been well received in the most prestigious journals (5-7). Also, recurrence of specific pregnancy outcomes within sibships and between generations provide new knowledge (8-11).

\section{SELECTIVE FERTILITY}

Especially Leiv Bakketeig, and his colleague Howard Hoffman from the US (NICHD, Bethesda), saw early the value of sibship data as the basis for research, and they published a series of unique papers in the period 1975-1986. Their focus was mostly on recurrence of perinatal events in successive sibs like small-forgestational age (SGA), preterm birth ( $<36$ weeks) and low birthweight $(<2500 \mathrm{~g})(12-14)$, but also weightspecific-perinatal mortality conditioned on outcome of previous births (15).

A study by Bakketeig and Hoffman that created a 


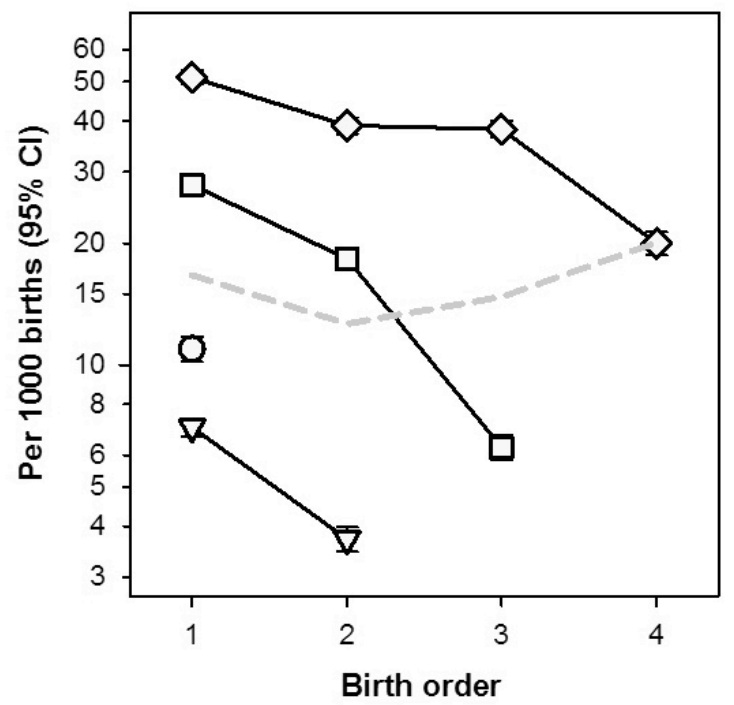

Figure 1. Perinatal mortality by birth order, stratified by number of pregnancies. Dashed, grey line: cross-sectional data. Singleton births, 1st birth 1967-86, mothers followed to 2006 .

lot of attention, was published in BMJ in 1979 (16). Based on sibship organize data, with an unorthodox analytical method, they challenged the traditional cross-sectional based J-shaped risk pattern of parity on perinatal mortality. Their results, focusing perinatal death in strata of parity (replicated in figure 1, based on MBRN: singleton births, first birth 1967-1986) demonstrated reduced mortality by increasing birth order within each of the fixed sibship size strata. Norman Mantel found the results interesting, but suggested reanalysis (17). Jean Golding called the results 'Perinatal epidemiology in Wonderland' (18), and suggested that the 'cross-sectional approach would have described the effects perfectly' and concluded that 'the so-called longitudinal approach to this problem leads up a blind alley' (19). In the figure, the trend based on crosssectional data is also shown.

The special approach Bakketeig and Hoffman applied is valuable in many ways - one is that it triggers a discussion of choice of unit of analysis. Their analytical strategy illustrated the complexity of perinatal data. Not acknowledging the heterogeneous risk between women, the strong effects of selective fertility (a tendency to control fertility on the basis of previous pregnancy outcomes), and changing effects due to maternal age and birth order (20) may distort and bias results and interpretations. One easy solution, when parity issues complicate a study, is to confine to first pregnancy only, however, this strategy can lose the target since fertility in itself holds important clues.

Women control their fertility, the number of children they want, and when to be pregnant. These selective processes change by time and strongly influences perinatal health. Causes of variation in fertility are many, probably the most important being age of the mother. Also, the loss of a child will often lead to a 'replacement' pregnancy, while the birth of a survi- ving, but severely malformed child, may alter plans. Conditions like preterm preeclampsia may itself be associated with reduced fertility. Allen Wilcox has good descriptions of the selective fertility topic in his book 'Fertility and pregnancy' (21).

High age dramatically reduces fertility. However, if the mother has a loss, fertility is increased (22). Also, sex of the last child matters $(23,24)$. After two children of the same sex, fertility is higher than after one of each; also twin pregnancy reduces fertility (23). Cesarean delivery reduces fertility, but more so if the infant survive than if stillborn or die in the perinatal period (25). Preeclampsia (7) and diabetes (26) both reduce the wish or ability for further reproduction.

\section{PRegnanCIES AND LONG TERM SURVIVAL OF WOMEN}

Norwegian studies have documented that having children prolongs life expectancy. In a series of articles, Grundy and Kravdal $(1,27,28)$ have studied the relation between reproductive history and maternal and paternal mortality. Compared to women with two or more children, the hazard of dying in the age range 45 68 years is 1.50 (95\% confidence interval (CI) 1.43 1.57) for women without children, and also elevated for women with only one child, 1.31 (95\% CI 1.26 1.37) (1). These excess risks are similar, but slightly lower, for men. In the follow-up study (27), they have found that these excess risks are seen in nearly all of eleven cause-of-death categories, and they have suggested that closely spaced births may negatively influence long term health of parents (28). These important results need scrutinizing by pregnancy complications and outcome of pregnancy.

In recent years there has been much focus on preeclampsia and maternal long term survival. In a frequently cited paper, Irgens et al. (5) showed that overall mortality is elevated especially in preterm preeclampsia, with a hazard ratio 2.7 (95\% CI 2.0-3.7). However, they found no elevated risk for the father, so the genetic predisposition for preeclampsia that works through the father $(11,29)$ is not reflected in long term paternal mortality. This study, as most other studies on maternal long term health and pregnancy outcome confined to first birth, without taking women's later reproduction into consideration. This is a natural strategy to avoid using the mother more than once (30).

In another Norwegian study, it was shown that the relation between preeclampsia and maternal cardiovascular disease (CVD) interacts with fertility (7). Especially after first preterm preeclampsia, the study showed a strong interaction in effect (hazard ratio for CVD death) between preeclampsia and number of lifetime pregnancies (one versus two or more), with a 9.4 (95\% CI 6.5-13.7) versus 3.7 (2.7-4.8) hazard ratio, respectively - both relative women with two or more pregnancies and no preeclampsia in first pregnancy. For term preeclampsia, the study showed that women with at least one pregnancy following the first 
preeclamptic had no excess risk for maternal death, 1.0 (0.9-1.1) - all causes combined.

This study is encouraging, if the effect is causal, since the majority of women with preeclampsia in first pregnancy, those who go on to have more pregnancies after the first ( $85 \%$ of women in Norway) is shown to have no excess early mortality linked to the preeclamptic condition. They do have a slight excess CVD mortality, but reduced risk for other causes of death, for instance death due to cancer. This is a good example of how the research based on a single pregnancy leads to misleading conclusion, while a more complete reproductive picture unveil strong heterogeneities in risk.

Unaffected sisters (or brothers) may be valuable for suggesting causal relations. The Norwegian Central Population Register (NCPR) link individuals to their mother and father, and through this resource we can identify sisters and brothers that are mothers and fathers in the birth registry. This link has been utilized in preeclampsia research.

In a recent study, Vikse et al. (31) used NCPR linked to MBRN and the Cause of Death Registry to study how preeclampsia is related to kidney disease. They showed that women with a preeclampic pregnancy had a 6-fold (hazard ratio 6.0; 95\% CI 4.4-8.1) risk for end stage renal disease (ESRD), but they could not find any excess risk for ESRD in unaffected sisters (1.0; 95\% CI 0.6-1.6). They concluded that 'familial aggregation of risk factors does not seem to explain increased risk for kidney disease after preeclampsia. These findings support the hypothesis that preeclampsia per se may lead to kidney damage', thus there is little support for a genetical or familial predisposition for disease as suggested for CVD by Irgens et al. (5). Not surpricingly, women with pregestational diabetes who have preeclampsia in the first pregnancy and deliver preterm are at increased risk for ESRD and early death. However, effects are found only in women who have one pregnancy, demonstrating again the importance of the sib-approach (26).

\section{THE NEW AGENDA - 'EARLY ORIGIN' AND 'LIFE COURSE' EPIDEMIOLOGY}

The last 25 years have largely changed the way we think of causes of disease, and especially the cause of adult diseases. 'Early origin', and 'life course epidemiology' hypotheses have increased the value of perinatal epidemiological data, and medical birth registries with long observation periods. Already in 1992 Robinson (32) suggested that the 'early origin of adult diseases' represents a shift, away from the traditional 'lifestyle' paradigm. The numerous studies, starting in the early 90s, of David Barker and his colleagues at the University of Southampton $(33,34)$, have inspired new research worldwide. Twenty years earlier, the Norwegian Anders Forsdahl reported on the relation between poor living conditions in childhood years in
Finnmark and high mortality in adulthood (35), but it was Barker who revitalized and expanded this idea. Barker himself had a flexible definition of 'early origin'; he has specified the origin to adult disease with intrauterine origin (1989), fetal (1990), infant (1990), developmental (2003), social (2007), placental (2010) and obstetric origin (2013).

Inspired by the success of the 'early origin' approach to chronic disease, life course epidemiology (36) was rapidly established as a new epidemiological discipline, especially in England. Life course epidemiology challenged the traditional aetiologic model for adult disease (i.e. stress, lack of exercise, bad nutrition) by acknowledging the work of Forsdahl and Barker: '... adult chronic disease is biologically 'programmed' during critical periods of growth and development in utero or early infancy. The extent to which these effects can be modified by later experience is a key question in life course epidemiology' (36, p. 3). Thus, the basic idea is that adult chronic disease not only has its origin in adult behavior and socioeconomic circumstances, but rather accumulates throughout life from gestation, childhood, adolescence, and later adult life. 'Life course epidemiology attempts to integrate biological and social risk processes rather than draw false dichotomies between them' (37).

Especially, researchers from England have been constructive in designing life course studies, both since they have pioneered the designs, but also because they have had long tradition with structured birth cohort materials for several selected years, and through these materials been able to link and update with new exposures and outcomes, for instance the Cohort of 1946 (38) and the Cohort of 1958 (39). The 1958 cohort has updated data in 1965, 1969, 1974, 1981, 1991, 1999, 2004, 2008, 2013. The original sample was based on 17,500 babies born in England, Scotland and Wales in 1958.

The Norwegian answer to these designs is the Norwegian Mother and Child Cohort Study (MoBa). $\mathrm{MoBa}$ has more focus on the pregnancy and the early period of the child's life than these English follow-up studies. The success of $\mathrm{MoBa}$ has recently been accounted for in Norsk Epidemiologi (40).

The new paradigm increases the value of well functioning population based registries. Being the oldest birth registry, the Medical Birth Registry of Norway is well suited to be a base for 'life course' studies. In a life course perspective, a birth registry can focus either the newborn or parents. Both the early origin and the life course hypotheses are built on data that are cross sectional. As a newborn, data on siblings may be of importance to the long term health prospects. However, using a medical birth registry in the health prospects of women (and men), the total reproductive experience all their pregnancies, as well as their own birth should be the foundation stone of the health profile. We can enlarge on these ideas through our sibling and generational data. 


\section{GENERATIONS}

\section{The classical dilemma - nature or nurture}

A problem with the early origin of adult diseases is that social and behavioral factors are inherited from one generation to the next. Also, few of Barker's initial articles had good adjustments for crucial social factors, like education and smoking during pregnancy. In a series of papers based on data from the Norwegian Mother and Child study (MoBa), utilizing one essential question 'Did your mother smoke when pregnant with you?', we have found that in utero exposure to cigarette smoke increases risks of stillbirth, fertility problems, obesity, hypertension, gestational diabetes, unfavorable plasma lipids and more (41-45). Smoking in pregnancy is socially inherited from mother to daughter, and may easily explain at least some of these results. A recent study has shown that a woman born with low birthweight is more often a smoker as an adult, even after adjusting for maternal education (46). Low birthweight in mothers may be due to grandmothers' smoking habits. In a fascinating study, Næss and colleagues (47) have found strong relations between CVD mortality in grandparents and grandchild birthweight, suggesting an important role of smoking during pregnancy. Thus, the social inheritance of smoking from mother to daughter explains part of the link between low birthweight and adult cardiovascular death - the increased risk of smoking in pregnancy is four fold in women with a mother who smoked during pregnancy relative other women. These Norwegian studies all show the complexity in causal inference, disentangling biological (genetic) and environmental factors. Part of the effect of early origin to adult diseases reported by Barker may be due to 'inherited' social factors.

\section{Birth order and performance in adulthood}

In another generation study we have focused on the mother's own birth order. It is well known that first births are more often growth retarded, premature or born after a preeclamptic pregnancy. Also, they are at higher risk for perinatal death than later born children. Since birthweight between generations are strongly correlated (48), it would be natural to assume that first born women would have children with lower birthweight than second or higher birth order women. We have found the opposite (49). First born women, compared to later born, have offspring with higher birthweight. Our interpretation is that the negative birth experience is overruled by the social setting of being first born. Birth order also has an effect on measured IQ, again with first born scoring highest. In a very interesting study, again based on sib data (50), Kristensen and Bjerkedal showed that if the first born dies, the next child will have higher IQ, even higher than the first born. The dynamic of being born first, second or last in a sequence of sibs holds fascinating variation. In the book 'Born to rebel', Frank Sulloway (51) has described the importance of birth order and performance in adulthood. The overall conclusion is that first born children typically are conservative and respectful of their parents, while later born are more open to experience and change, are rebellious and even more creative.

\section{Fertility, reproduction and recurrence of events}

Recurrence of pregnancy outcomes between generations is an obvious topic when generational data are available, and it holds a potential for understanding causes of 'early origin'. With data covering the years 1967-2014, 48 years, we now have almost 10 years (1967-76) with complete two-generations data, i.e. for women and men born in these early years we have records covering their complete reproduction within the follow-up years. We have, among other conditions, studied malformations, preeclampsia, preterm and postterm birth $(10,11,52-54)$ but also relations between preterm birth and low birthweight in the first generation and perinatal mortality in the next.

An important issue of these generational data is lack of reproduction in the next generation - women and men born with low birtweight, born preterm, or born with a malformation, have reduced fertility as adults $(3,4,10,52)$ and this reduction seems to be higher for males than for females.

\section{Birthweight and gestational age in $1^{\text {st }}$ generation, perinatal survival in the next}

Likewise, preterm born mothers have excess risk for perinatal loss of own children, while we observe no such effect for preterm born fathers $(55,56)$ and this effect is especially high when the mothers deliver twins (57).

In studies of variation of birthweight or gestational age for the mother's own pregnancy, and consequences for offspring perinatal survival we find strong 'doseresponse' relations, with high mortality for preterm and low birthweight born mothers. We will suggest this effect as evidence for an 'early origin' mechanism, the preterm born mother have reduced capacity to deliver a healthy baby $(55,56)$. This is particularly observed when preterm born mothers are pregnant with twins, with 3.8 (95\% CI 1.6-9.4), 2.4 (1.3-4.5) and 1.9 (1.23.0) excess risk for extreme preterm ( $<32$ weeks), moderate preterm (32-34 weeks) and slight preterm birth (35-36 weeks), respectively, all compared to 3742 weeks gestation. The effect was especially high after assisted reproductive therapy (ART) pregnancy (57).

A paradoxical results is the relative importance of maternal birthweight on weight specific offspring mortality: if the child is born small, the survival is better when the mother herself also was small at birth (55). This effect is equivalent to what we find for a similar evaluation between first and second sib in maternal successive sibs $(55,58,59)$. 


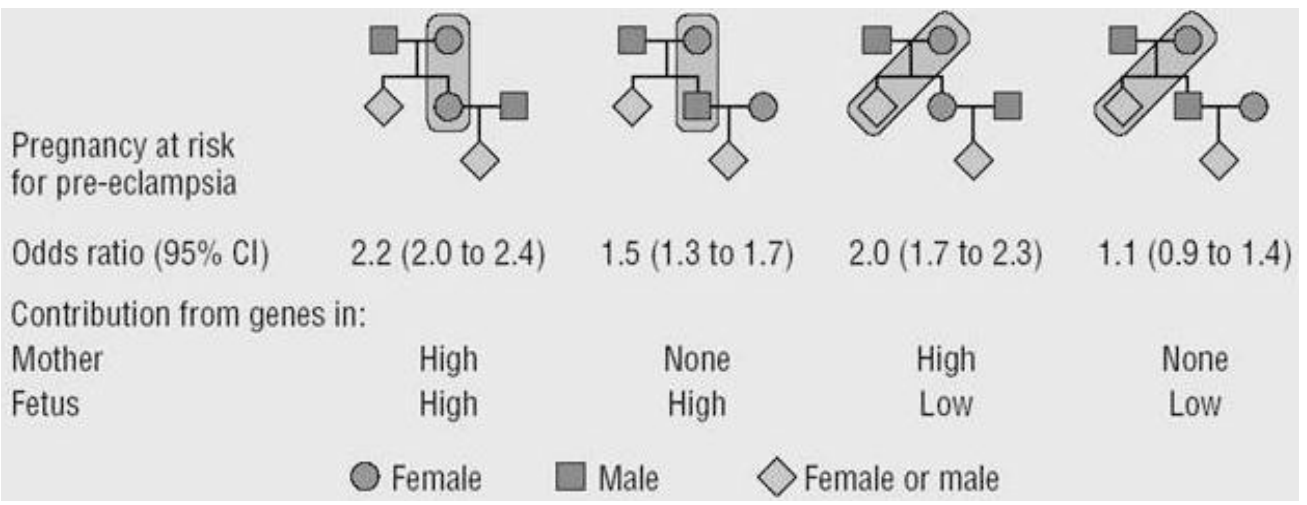

Figure 2. Generational recurrence of preeclampsia: First panel: Risk of preeclampsia in own pregnancy for women born after a preeclamptic pregnancy. Second panel: Risk of preeclampsia in partner's pregnancy for men born after a preeclamptic pregnancy. Third panel: Risk of preeclampsia in pregnancy for unaffected sisters. Fourth panel: Risk of preeclampsia in partner's pregnancy for unaffected brothers. Figure reproduced from ref. (11), (C) 2015 BMJ Publishing Group Ltd.

\section{Differentiating maternal and fetal causes for disease}

Two generational materials on reproduction are especially valuable when we have the opportunity to compare recurrence from mother to offspring with recurrence from father to offspring. Genetic influence from the father can only be expressed through the fetus. It is natural to assume a similar fetal influence also coming from the mother. In addition, the mother's own genes and constitution have independent and strong impact on the fetus. In studies where we observe the same recurrence from the father as from the mother, it is natural to assume that only fetal genes are at work, and when there is no recurrence effect from the father we can assume that only the mothers own genes or mitochondrial inheritance are at work.

\section{Malformations through generations}

Our first generational recurrence focus was on malformations from parents to offspring $(10,52)$, inspired by our previous sib study on recurrence from first to second pregnancy (9). Overall, we found recurrence to be stronger from father $(\mathrm{OR}=2.4 ; 95 \% \mathrm{CI} 1.7-2.8)$ than from mother $(\mathrm{OR}=1.6 ; 1.2-2.0)$. We found strong recurrence for same type of defect, both from mother $(\mathrm{OR}=6.8 ; 4.5-10.0)$ and father $(\mathrm{OR}=6.5 ; 4.0-10.4)$. For other defects we found no excess risk from the mother $(\mathrm{OR}=1.0 ; 0.7-1.4)$, while a significant effect $(\mathrm{OR}=1.8$; 1.3-2.5) from the father. Surely, the results suggest fetal causes since the father's influence is stronger than the mother's (60).

\section{Breech presentation and generations}

Recurrence of breech presentation is surprising (61). In the literature it was difficult to find any mentioning of the rule of the father, however we found that the recurrence of breech presentation from one generations to the next to be as strong from men who themselves were delivered in breech, as from women who were delivered in breech (OR were both 2.2, with 95\% confidence intervals 1.8-2.7 and 1.9-2.5, respectively). These results were for term birth only, no recurrence could be demonstrated for men or women born preterm. The interpretation is again that there is a strong familial predisposition for term breech delivery that is due to genetic inheritance, predominantly through the fetus.

\section{Gestational age and generations}

Gestational age between generations show interestingly complex relations. Population based generational data for preterm birth is a good example of 'macro-genetic' relations that can guide or target the search for specific genes. We find a clear maternal effect for preterm birth between generations, but there is no fetal effect, i.e. a preterm born father does not elevate the risk for preterm birth in the next generation (53). There is however both a maternal and fetal effect for postterm birth (54), and this is clearly linked to a similar effect within the term (37-42) weeks (62). We especially find an effect of paternal birthweight where high birthweight reduces the gestational age in the next generation (62). The conclusion we have for gestational age confined to the term weeks, is that the fetus and the mother play equally important roles in determining time of delivery.

\section{Preeclampsia and generations}

Another example of generational effects is for preeclampsia. Fathers who were born after a pregnancy complicated by preeclampsia increased the risk of preeclampsia in the pregnancy of their partner with $50 \%$ $(\mathrm{OR}=1.5 ; 95 \% \mathrm{CI} 1.3-1.7)$, while the risk was increased $120 \%(\mathrm{OR}=2.2 ; 2.0-2.4)$ for women who themselves were born after a preeclamptic pregnancy (11). In this study we also evaluated the risk for unaffected sisters and brothers, and we found a $100 \%$ increase in risk for the sister $(\mathrm{OR}=2.0 ; 1.7-2.3)$, while no effect for the brother. Thus, the interpretation is that preeclampsia is mainly caused by maternal factors, but there is also an effect that works through the fetus itself. Figure 2 (from ref. 11) illustrates the four sets of risk scenarios.

This design was also used for recurrence of hyperemesis across generations (8). We found no evidence 
for fetal effects, but a relatively strong maternal effect from the affected woman to daughters as well as from older unaffected sisters to their daughters - a 3-fold increase.

\section{Cerebral palsy and family risk}

Conditions in pregnancy like birth asphyxia, preterm birth, intrauterine growth and certain malformations have been shown to be strongly associated with cerebral palsy, the most common cause of physical disability in children. In a recent study, Tollånes et al. (63) studied the familial risk of cerebral palsy based on data for social insurance benefits, linked to MBRN. They demonstrated strong recurrence risks between twins ( $\mathrm{OR}=15.6 ; 95 \% \mathrm{CI} 9.8-25)$, and between siblings in general $(\mathrm{OR}=9.2 ; 6.4-13)$, but weaker effects for half siblings. Parents and offspring also gave relatively high recurrence estimates. Interestingly, the risk relations increased after excluding preterm born individuals, suggesting that inheritance of cerebral palsy is stronger between term born individuals.

\section{SIBLING RISKS}

\section{New partner and interval between pregnancies}

In a study on malformations and siblings, we evaluated the effect of 'new partner' and 'new municipality' (9) and found that the recurrence of same defect was strongest for women with same partner and same municipality $(\mathrm{OR}=11.6 ; 95 \%$ CI 9.3-14.0), and weakest for women with new partner and who also had moved $(\mathrm{OR}=4.9 ; 1.7-8.2)$. These differences suggest an effect of the environment.

The occurrence of preeclampsia is strongly related to parity, and cross-sectional analyses show that the occurrence is stronger in first $(5-6 \%)$ than in later $(1.5 \%)$ pregnancies. However, in the early $1990 \mathrm{~s}$ several research groups observed that a new partner in second pregnancy almost eliminated this reduction, the mother was back to being 'nullipara'; and immunological mechanisms was suggested (64-67). A series of studies from the Nordic countries suggested that distance between pregnancies was a strong confounder (68-70). It was shown that a new partner was associated with prolonged interval, and that interval increased the risk of preeclampsia. Adjusting for distance, the increased risk for preeclampsia in second pregnancy due to a new partner disappeared, in fact a new partner slightly reduced the risk of preeclampsia. This reduction may be due to social differences, with more smoking in women with a new partner, and indeed in a recent study from Sweden (71), further adjusting for maternal smoking demonstrated no difference in effect on preeclampsia by a new partner.

On the other hand, change of partner is in general associated with excess risk of adverse pregnancy outcome. In a study where $2^{\text {nd }}$ pregnancy outcomes for women with new partners were compared to that of women with same partner for both $1^{\text {st }}$ and $2^{\text {nd }}$ pregnancy, infant mortality, preterm birth $(<37$ weeks) and low birth weight $(<2500$ gram $)$ were all elevated with adjusted ORs corresponding to 1.8 (95\% CI 1.62.1), 2.0 (1.9-2.1) and 2.5 (2.3-2.6), respectively (72). Women with low education tend to change partner more than those with higher education. The relative number of women with new partners is increasing, both between first and second, and between second and third pregnancy. Less than $5 \%$ of women had a new partner in the second pregnancy in the period 1967-1976. This increased to almost $15 \%$ in the year 2000. A similar increase for a new partner is observed also following the second pregnancy.

Recently we evaluated the association between preeclampsia and assisted reproductive technology (ART), again using sibship data (73). A new partner indirectly increased the risk for preeclampsia since a new partner increase the distance, and this prolonged distance was associated with ART. Thus, a new partner leads to ART pregnancy and preeclampsia, both caused by a prolonged time between pregnancies. In fact, ART pregnancies, more than other pregnancies, leads to preeclampsia since these women are less likely to smoke.

Grundy and Kravdal used data from NCPR (1,27, $28)$ to study long term survival of women and men. Lie et al. (29) also used data from NCPR, linked to MBRN, to identify brothers and sisters and their pregnancies. They showed that if a woman becomes pregnant by a man who earlier fathered a preeeclamptic pregnancy to another woman, her risk for preeclampsia is increased $(\mathrm{OR}=1.8 ; 95 \%$ CI 1.2-2.6). They also showed that if two sisters have the same father but different mothers, the risk for recurrence for preeclampsia is again 1.8 (1.01-2.9).

\section{Adverse pregnancy events, evaluation of the other pregnancies}

We have evaluated recurrence risks for adverse outcome in successive sibling. In the study of malformations within sibships, we found that the recurrence was much higher for a similar malformation $(\mathrm{OR}=7.6 ; 95 \%$ CI 6.5-8.8) than for dissimilar malformations (1.5; 1.31.7) (9). The recurrences of same defects varied largely between defects (from 5 to 45), but the recurrences were all low for dissimilar defects. Recurrence was reduced with a new partner, but even more with a new address. Much the same results are seen for other conditions like sudden infant death (SIDS) and stillbirths. Early we evaluated recurrence risk of SIDS in sibships (74), and even 12 years later we found a similar risk estimate $(\mathrm{OR}=5.8 ; 2.1-13.2)$ (75). Evaluating 7 different causes of death in the $1^{\text {st }}$ year of life, no other cause was related to SIDS. For stillbirths, the recurrence risk was especially high for another stillbirth in the same gestational period. Extremely high recurrence risk was observed for early stillbirths, 20-27 weeks $(\mathrm{OR}=26 ; 20-33)(75,76)$, but also recurrence loss in 
weeks 28-32, and 33-36 was high, while the recurrence risk was low and not significant for a loss in the term weeks followed by a loss in early preterm. In general, the recurrence is stronger for the same than for different types of losses.

In a series of articles, we have evaluated the variation in birthweight of siblings (and other characteristics of the birth or the pregnancy) in families with one or more SIDS cases, one or more children with malformations, one or more perinatal deaths. The patterns of birthweight in the affected and the unaffected are very different depending of the condition. In sibships with malformations, the birthweights were 250-400 grams reduced relative to the same parity births in sibships without malformations, while the birthweights for the non-malformed were very close (and nonsignificantly different) to that of families without malformations for the same parity (77). This pattern was so even in families with three pregnancies where two of the fetuses had malformations.

In families with SIDS, however, there is a negative effect on birthweight even for unaffected siblings $(78,79)$ Also in families with one or more perinatal losses, the birthweight was reduced for non-affected siblings (80).

The value of sibship data was particularly obvious in birth characteristics of non-ART pregnancies for women with one or more ART pregnancy. The conclusion of the study was that the observed variation in adverse outcome due to assisted fertilization could be attributed to factors leading to infertility rather than to the reproductive technology in itself (81).

\section{The population average birthweight does not apply equally well to all women}

Based on sibship data it was evident that the population average birthweight (around 3500 grams) is not the norm for all women. Admittedly a mother that smokes heavily in all her pregnancies will have a reduction in birthweight (200-300 grams) for all her births. However, given a relatively small child in the first pregnancy $(<2500$ grams), compared to a large first child ( $\geq 4500$ grams), the difference in birthweight for second births for these two groups of mothers is close to 1000 grams (58), and this strong relation persists after accounting for gestational age (59). A very similar result is seen when evaluating variation in gestational age in itself (82). These differences in expected size or gestational age for a second child have consequences for risk evaluations; for instance perinatal mortality is twice for a preterm born child with an older sibling born to term (40-41 weeks), compared to an older sibling born early preterm (35-36 weeks) (82). These results led us to suggest 'customized' birthweight by gestational age standards, accounting for birthweight of previous births to the same mother (and for first births similarly utilized the mothers own birth weight) (59). Certainly, it is better to account for the birthweight of previous pregnancies than to adjust for parity. Also, it is our suggestion that previous pregnancies are better predictors for birthweight in the next pregnancy than height or weight of the mother, as used in current 'customized' standards $(83,84)$. MBRN has since 2007 registered height and weight, so we can now evaluate the value of maternal height and weight against birthweight and gestational age of previous births as resources for customizing growth standards.

\section{THE IMPORTANCE OF DEPENDENCIES IN SUCCESSIVE PREGNANCIES}

The complicating issue of lack of independence in successive pregnancy outcomes has led researchers to study only the first pregnancy to the mother, especially when studying long term survival of the parents $(5,30)$. This selection approach is not ideal, since it excludes around $60 \%$ of all pregnancies. Also, we and others have shown that the presence of further pregnancies may have an impact on maternal health.

For studies of outcome of pregnancy, or survival of the child, it is customary to adjust for parity. In a commentary on when to use pregnancy history in studies of reproductive failure (85), Jørn Olsen concludes that 'proper adjustment for past pregnancy history goes much further than just adjustment for parity'.
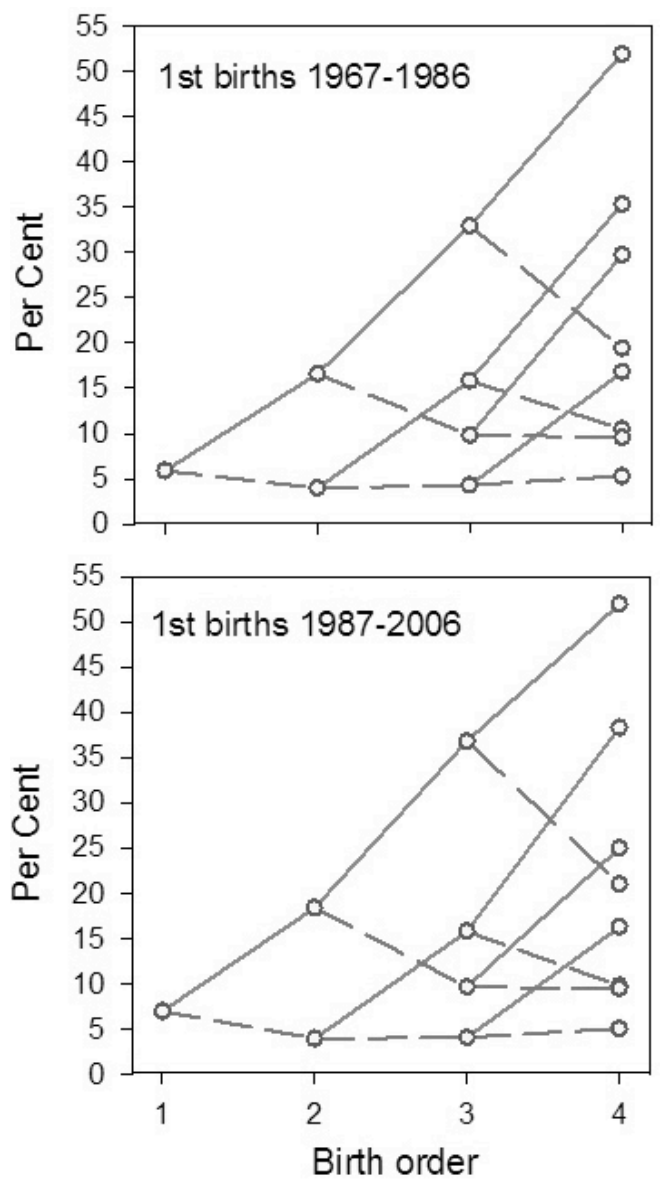

Figure 3. Risk for preterm birth, 1 st to 4 th singleton birth, by outcome of previous births. Solid lines: previous preterm. Dashed lines: previous term. 
Adjusting for parity cannot be a substitute for lack of sibship organized data. Many problems in perinatal epidemiology need the mother as the unit of analysis, not the single child. Even the practice to account for dependencies (for instance by use of procedures in STATA by using the mother as a 'cluster' in the analysis) is not optimal, since this strategy will camouflage the strong effects in the sib relations, also the sequence of events is lost.

Studying the next pregnancy conditional on outcomes of previous pregnancies will provide clinical useful results. As a final example we have graphed the recurrence of preterm pregnancies in successive pregnancies $\left(1^{\text {st }}\right.$ to $\left.4^{\text {th }}\right)$ in two independent periods (figure 3 ). We have previously presented similar graphs for perinatal death and preeclampsia $(86,87)$. For preterm birth the results are remarkably consistent by period, and if anything, the recurrence risk is higher in the last period.

We have with this overview tried to convince the reader that the correlated structure in perinatal data provide huge research opportunities. The dependencies in successive pregnancies hold important clues for risk heterogeneity between women. Also, intergenerational data reveal strong influence of socioeconomic and behavioral factors, not only genetic inheritance $(46,49)$.

\section{REFERENCES}

1. Grundy E, Kravdal Ø. Reproductive history and mortality in late middle age among Norwegian men and women. Am J Epidemiol 2008; 167 (3): 271-9.

2. Haig D. Genetic conflicts in human pregnancy. Q Rev Biol 1993; 68: 495-532.

3. Moster D, Lie RT, Markestad T. Long-term medical and social consequences of preterm birth. N Engl J Med 2008; 359 (3): 262-73.

4. Swamy GK, Østbye T, Skjærven R. Association of preterm birth with long-term survival, reproduction, and nextgeneration preterm birth. JAMA 2008; 299 (12): 1429-36.

5. Irgens HU, Reisæter L, Irgens LM, Lie RT. Long term mortality of mothers and fathers after pre-eclampsia: population based cohort study. BMJ 2001; 323 (7323): 1213-7.

6. Vikse BE, Irgens LM, Leivestad T, Skjærven R, Iversen BM. Preeclampsia and the risk of end-stage renal disease. $N$ Engl J Med 2008; 359 (8): 800-9.

7. Skjærven R, Wilcox AJ, Klungsøyr K, Irgens LM, Vikse BE, Vatten LJ, et al. Cardiovascular mortality after preeclampsia in one child mothers: prospective, population based cohort study. BMJ 2012; 345: e7677.

8. Vikanes A, Skjærven R, Grjibovski AM, Gunnes N, Vangen S, Magnus P. Recurrence of hyperemesis gravidarum across generations: population based cohort study. BMJ 2010; 340: c2050.

9. Lie RT, Wilcox AJ, Skjærven R. A population-based study of the risk of recurrence of birth defects. $N$ Engl J Med 1994; 331 (1): 1-4.

10. Skjærven R, Wilcox AJ, Lie RT. A population-based study of survival and childbearing among female subjects with birth defects and the risk of recurrence in their children. N Engl J Med 1999; 340 (14): 1057-62.

11. Skjærven R, Vatten LJ, Wilcox AJ, Rønning T, Irgens LM, Lie RT. Recurrence of pre-eclampsia across generations: exploring fetal and maternal genetic components in a population based cohort. BMJ 2005; 331 (7521): 877.

12. Bakketeig LS, Bjerkedal T, Hoffman HJ. Small-for-gestational age births in successive pregnancy outcomes: results from a longitudinal study of births in Norway. Early Hum Dev 1986; 14 (3-4): 187-200.

13. Bakketeig LS, Hoffman HJ, Harley EE. The tendency to repeat gestational age and birth weight in successive births. Am J Obstet Gynecol 1979; 135 (8): 1086-103.

14. Hoffman HJ, Bakketeig LS. Heterogeneity of intrauterine growth retardation and recurrence risks. Semin Perinatol $1984 ; 8$ (1): 15-24.

15. Bakketeig LS, Hoffman HJ. The tendency to repeat gestational age and birth weight in successive births, related to perinatal survival. Acta Obstet Gynecol Scand 1983; 62 (5): 385-92.

16. Bakketeig LS, Hoffman HJ. Perinatal mortality by birth order within cohorts based on sibship size. BMJ $1979 ; 2$ (6192): 693-6.

17. Mantel N. Perinatal mortality by birth order. BMJ 1979; 2: 1147.

18. Golding J. Perinatal epidemiology in Wonderland. BMJ 1979; 2: 1436.

19. Golding J, Butler NR, Newcombe RG. Analysis of completed reproductive histories: a cautionary tale. J Epidemiol Community Health 1983; 37 (1): 78-81.

20. Wilcox AJ, Gladen BC. Spontaneous abortion: the role of heterogeneous risk and selective fertility. Early Hum Dev 1982; 7 (2): 165-78

21. Wilcox AJ. Fertility and Pregnancy. An Epidemiologic Perspective. New York: Oxford University Press, 2010.

22. Skjærven R, Wilcox AJ, Lie RT, Irgens LM. Selective fertility and the distortion of perinatal mortality. $A m J$ Epidemiol 1988; 128 (6): 1352-63.

23. Bjerkedal T, Erickson JD. Association of birth outcome with subsequent fertility. Am J Obstet Gynecol 1983 ; 147 (4): 399-404.

24. Lippert T, Skjærven R, Salvesen KA. [Why do some women only give birth to boys or to girls?]. Tidsskr Nor Legeforen 2005; 125 (24): 3414-7.

25. Tollanes MC, Melve KK, Irgens LM, Skjærven R. Reduced fertility after cesarean delivery: a maternal choice. Obstet Gynecol 2007; 110 (6): 1256-63. 
26. Sandvik MK, Iversen BM, Irgens LM, Skjærven R, Leivestad T, Softeland E, et al. Are adverse pregnancy outcomes risk factors for development of end-stage renal disease in women with diabetes? Nephrol Dial Transplant 2010; 25 (11): 3600-7.

27. Grundy E, Kravdal Ø. Fertility history and cause-specific mortality: a register-based analysis of complete cohorts of Norwegian women and men. Soc Sci Med 2010; 70 (11): 1847-57.

28. Grundy E, Kravdal Ø. Do short birth intervals have long-term implications for parental health? Results from analyses of complete cohort Norwegian register data. J Epidemiol Community Health 2014; 68 (10): 958-64.

29. Lie RT, Rasmussen S, Brunborg H, Gjessing HK, Lie-Nielsen E, Irgens LM. Fetal and maternal contributions to risk of pre-eclampsia: population based study. BMJ 1998; 316 (7141): 1343-7.

30. Davey Smith G, Hypponen E, Power C, Lawlor DA. Offspring birth weight and parental mortality: prospective observational study and meta-analysis. Am J Epidemiol 2007; 166 (2): 160-9.

31. Vikse BE, Irgens LM, Karumanchi SA, Thadhani R, Reisæter AV, Skjærven R. Familial factors in the association between preeclampsia and later ESRD. Clin J Am Soc Nephrol 2012; 7 (11): 1819-26.

32. Robinson RJ. Is the child father of the man? BMJ 1992; 304 (6830): 789-90.

33. Barker DJP. Fetal and infant origins of adult disease. London: British Medical Publishing, 1992.

34. Barker DJP. Mothers, babies and health in later life. Edinburgh: Churchill Livingstone, 1998.

35. Forsdahl A. [Points which enlighten the high mortality rate in the county of Finnmark. Can the high mortality rate today be a consequence of bad conditions of life in childhood and adolescence?]. Tidsskr Nor Lageforen 1973; 93 (10): 661-7.

36. Kuh D, Ben-Shlomo Y. A life course approach to chronic disease epidemiology (2nd edition). Oxford: Oxford University Press, 2004.

37. Kuh D, Ben-Shlomo Y, Lynch J, Hallqvist J, Power C. Life course epidemiology. J Epidemiol Community Health 2003; 57 (10): 778-83.

38. Wadsworth M, Kuh D, Richards M, Hardy R. Cohort Profile: The 1946 National Birth Cohort (MRC National Survey of Health and Development). Int J Epidemiol 2006; 35 (1): 49-54.

39. Power C, Elliott J. Cohort profile: 1958 British birth cohort (National Child Development Study). Int J Epidemiol 2006; 35 (1): 34-41.

40. Vejrup K, Haugan A, Magnus P, editors. The Norwegian Mother and Child Cohort Study - history, scientific activities and future opportunities. Norsk Epidemiologi 2014; 24 (1-2).

41. Ye X, Skjærven R, Basso O, Baird DD, Eggesbø M, Cupul Uicab LA, et al. In utero exposure to tobacco smoke and subsequent reduced fertility in females. Hum Reprod 2010; 25 (11): 2901-6.

42. Cupul-Uicab LA, Baird DD, Skjærven R, Saha-Chaudhuri P, Haug K, Longnecker MP. In utero exposure to maternal smoking and women's risk of fetal loss in the Norwegian Mother and Child Cohort (MoBa). Hum Reprod $2011 ; 26$ (2): 458-65.

43. Cupul-Uicab LA, Ye X, Skjærven R, Haug K, Longnecker MP. Reproducibility of reported in utero exposure to tobacco smoke. Ann Epidemiol 2011; 21 (1): 48-52.

44. Cupul-Uicab LA, Skjærven R, Haug K, Melve KK, Engel SM, Longnecker MP. In utero exposure to maternal tobacco smoke and subsequent obesity, hypertension, and gestational diabetes among women in the MoBa cohort. Environ Health Perspect 2012; 120 (3): 355-60.

45. Cupul-Uicab LA, Skjærven R, Haug K, Travlos GS, Wilson RE, Eggesbø M, et al. Exposure to tobacco smoke in utero and subsequent plasma lipids, ApoB, and CRP among adult women in the MoBa cohort. Environ Health Perspect 2012; 120 (11): 1532-7.

46. Kvalvik LG, Skjærven R, Klungsøyr K, Vollset SE, Haug K. Can 'early programming' be partly explained by smoking? Results from a prospective, population-based cohort study. Paediatr Perinat Epidemiol 2015; 29 (1): 50-9.

47. Næss Ø, Stoltenberg C, Hoff DA, Nystad W, Magnus P, Tverdal A, et al. Cardiovascular mortality in relation to birth weight of children and grandchildren in 500,000 Norwegian families. Eur Heart J 2013; 34 (44): 3427-36.

48. Lunde A, Melve KK, Gjessing HK, Skjærven R, Irgens LM. Genetic and environmental influences on birth weight, birth length, head circumference, and gestational age by use of population-based parent-offspring data. Am $J$ Epidemiol 2007; 165 (7): 734-41.

49. Nordtveit TI, Melve KK, Skjærven R. Intergenerational birth weight associations by mother's birth order the mechanisms behind the paradox: a population-based cohort study. Early Hum Dev 2009; 85 (9): 577-81.

50. Kristensen P, Bjerkedal T. Explaining the relation between birth order and intelligence. Science 2007; 316 (5832): 1717.

51. Sulloway FJ. Born to rebel. Birth order, Family Dynamics, and Creative Lives. New York: Pantheon, 1996.

52. Lie RT, Wilcox AJ, Skjærven R. Survival and reproduction among males with birth defects and risk of recurrence in their children. JAMA 2001; 285 (6): 755-60.

53. Wilcox AJ, Skjærven R, Lie RT. Familial patterns of preterm delivery: maternal and fetal contributions. Am $J$ Epidemiol 2008; 167 (4): 474-9.

54. Morken NH, Melve KK, Skjærven R. Recurrence of prolonged and post-term gestational age across generations: maternal and paternal contribution. BJOG 2011; 118 (13): 1630-5.

55. Skjærven R, Wilcox AJ, Øyen N, Magnus P. Mothers' birth weight and survival of their offspring: population based study. BMJ 1997; 314 (7091): 1376-80.

56. Nordtveit TI, Melve KK, Skjærven R. Mothers' and fathers' birth characteristics and perinatal mortality in their offspring: a population-based cohort study. Paediatr Perinat Epidemiol 2010; 24 (3): 282-92. 
57. Tandberg A, Melve KK, Nordtveit TI, Bjørge T, Skjærven R. Maternal birth characteristics and perinatal mortality in twin offspring. An intergenerational population-based study in Norway, 1967-2008. BJOG 2011; 118 (6): 698-705.

58. Skjærven R, Wilcox AJ, Russell D. Birthweight and perinatal mortality of second births conditional on weight of the first. Int J Epidemiol 1988; 17 (4): 830-8.

59. Skjærven R, Gjessing HK, Bakketeig LS. New standards for birth weight by gestational age using family data. Am $J$ Obstet Gynecol 2000; 183 (3): 689-96.

60. Lie RT. Intergenerational exchange and perinatal risks: a note on interpretation of generational recurrence risks. Paediatr Perinat Epidemiol 2007; 21 Suppl 1: 13-8.

61. Nordtveit TI, Melve KK, Albrechtsen S, Skjærven R. Maternal and paternal contribution to intergenerational recurrence of breech delivery: population based cohort study. BMJ 2008; 336 (7649): 872-6.

62. Lie RT, Wilcox AJ, Skjærven R. Maternal and paternal influences on length of pregnancy. Obstet Gynecol $2006 ; 107$ (4): 880-5.

63. Tollånes MC, Wilcox AJ, Lie RT, Moster D. Familial risk of cerebral palsy: population based cohort study. BMJ 2014; 349: g4294.

64. Dekker GA, Sibai BM. The immunology of preeclampsia. Semin Perinatol 1999; 23 (1): 24-33.

65. Dekker G. The partner's role in the etiology of preeclampsia. J Reproduct Immunol 2002; 57 (1-2): 203-15.

66. Dekker G, Robillard PY, Roberts C. The etiology of preeclampsia: the role of the father. J Reproduct Immunol 2011; 89 (2): 126-32.

67. Robillard PY, Dekker G, Chaouat G. Fourteen years of debate and workshops on the immunology of preeclampsia. Where are we now after the 2012 workshop? J Reproduct Immunol 2014; 101-102: 62-9.

68. Skjærven R, Wilcox AJ, Lie RT. The interval between pregnancies and the risk of preeclampsia. N Engl J Med 2002; 346 (1): 33-8.

69. Basso O, Christensen K, Olsen J. Higher risk of pre-eclampsia after change of partner. An effect of longer interpregnancy intervals? Epidemiology 2001; 12 (6): 624-9.

70. Trogstad LI, Eskild A, Magnus P, Samuelsen SO, Nesheim B-I. Changing paternity and time since last pregnancy; the impact on pre-eclampsia risk. A study of 547238 women with and without previous pre-eclampsia. Int J Epidemiol $2001 ; 30$ (6): 1317-22.

71. Wikström A-K, Gunnarsdóttir J, Cnattingius S. The paternal role in pre-eclampsia and giving birth to a small for gestational age infant; a population-based cohort study. BMJ Open 2012; 2 (4).

72. Vatten LJ, Skjærven R. Effects on pregnancy outcome of changing partner between first two births: prospective population study. BMJ 2003; 327 (7424): 1138.

73. Tandberg A, Klungsøyr K, Romundstad L, Skjærven R. Pre-eclampsia and assisted reproductive technologies: consequences of advanced maternal age, interbirth intervals, new partner and smoking habits. BJOG 2015; 122 (7): 915-22.

74. Irgens LM, Skjærven R, Peterson DR. Prospective assessment of recurrence risk in sudden infant death syndrome siblings. J Pediatr 1984; 104 (3): 349-51.

75. Øyen N, Skjærven R, Irgens LM. Population-based recurrence risk of sudden infant death syndrome compared with other infant and fetal deaths. Am J Epidemiol 1996; 144 (3): 300-5.

76. Melve KK, Skjærven R, Rasmussen S, Irgens LM. Recurrence of stillbirth in sibships: Population-based cohort study. Am J Epidemiol 2010; 172 (10): 1123-30.

77. Melve KK, Skjærven R. Families with birth defects: is birth weight of nonmalformed siblings affected? Am $J$ Epidemiol 2002; 155 (10): 932-40.

78. Øyen N, Skjærven R, Little RE, Wilcox AJ. Fetal growth retardation in sudden infant death syndrome (SIDS) babies and their siblings. Am J Epidemiol 1995; 142 (1): 84-90.

79. Øyen N, Haglund B, Skjærven R, Irgens LM. Maternal smoking, birthweight and gestational age in sudden infant death syndrome (SIDS) babies and their surviving siblings. Paediatr Perinat Epidemiol 1997; 11 Suppl 1: 84-95.

80. Melve KK, Skjærven R, Øyen N. Families with a perinatal death: is there an association between the loss and the birthweight of surviving siblings? Paediatr Perinat Epidemiol 2002; 16 (1): 23-32.

81. Romundstad LB, Romundstad PR, Sunde A, von During V, Skjærven R, Gunnell D, et al. Effects of technology or maternal factors on perinatal outcome after assisted fertilisation: a population-based cohort study. Lancet $2008 ; 372$ (9640): 737-43.

82. Melve KK, Skjærven R, Gjessing HK, Øyen N. Recurrence of gestational age in sibships: implications for perinatal mortality. Am J Epidemiol 1999; 150 (7): 756-62.

83. Figueras F, Gardosi J. Should we customize fetal growth standards? Fetal Diagn Ther 2009; 25 (3): $297-303$.

84. Gardosi J, Figueras F, Clausson B, Francis A. The customised growth potential: an international research tool to study the epidemiology of fetal growth. Paediatr Perinat Epidemiol 2011; 25 (1): 2-10.

85. Olsen J. Options in making use of pregnancy history in planning and analysing studies of reproductive failure. $J$ Epidemiol Community Health 1994; 48 (2): 171-4.

86. Skjærven R, Irgens LM, Lie RT, Bjerkedal T. Parity specific perinatal mortality. A longitudinal study based on sibships. Paediatr Perinat Epidemiol 1987; 1 (2): 163-83.

87. Skjærven R, Melve KK, Vatten LJ. The epidemiology of preeclampsia with focus on family data. In: Pijnenborg R, Brosens I, Romero R, editors. Placental Bed Disorders. Cambridge: Cambridge University Press, 2010. 